\title{
Luis Gutiérrez Soto en Sevilla. 1954-1965
}

\section{Luis Gutiérrez Soto in Seville. 1954-1965}

\author{
R. Carbajal-Ballell (*)
}

\section{RESUMEN}

Entre 1954 y 1965 Luis Gutiérrez Soto proyectó y construyó en Sevilla tres inmuebles de vivienda colectiva de gran dimensión para la Plaza de Cuba, gran puerta de ingreso al ensanche de Triana en Los Remedios. Si bien estas edificaciones se encuentran recogidas en diversos catálogos de arquitectura contemporánea (1) (2) y guías de arquitectura de la ciudad (3), en los estudios completos de su obra únicamente aparecen recogidas en los índices generales, sin que haya sido considerada su incidencia sobre el contexto arquitectónico sevillano de la época. Este artículo pretende señalar la trascendencia que estos tres proyectos tuvieron en la implantación y el desarrollo posterior de esta tipología en la ciudad de Sevilla, llegando a convertirse en referentes esenciales para arquitectos locales y futuros usuarios de estas viviendas.

Palabras clave: Luis Gutiérrez-Soto, Vivienda Máxima, Sevilla.

\section{ABSTRACT}

Between 1954 and 1965 Luis Gutiérrez Soto designed and built in Seville three buildings of large scale collective houses in the Cuba Square, the great gateway to the new extension of Triana in Los Remedios. While these buildings are included in several catalogs of contemporary architecture (1) (2) and architectural city guides (3), in the different studies of his work, they are cited only in the general indices, and the impact on the sevillian architectural context has not been considered yet. This article aims to point out the importance that these projects were in the implementation and further development of this residential typology in the city of Seville, becoming essential typological models for both local architects and future residents of these homes.

Keywords: Luis Gutiérrez-Soto, Maximun Houses, Seville.

(*) Departamento Proyectos Arquitectónicos ETSA. Universidad de Sevilla.

Persona de contacto/Corresponding author: rcarbajal@us.es (R. Carbajal-Ballell)

ORCID: http://orcid.org/oooo-0002-0506-2150 (R. Carbajal-Ballell)

Cómo citar este artículo/Citation: Carbajal-Ballell, R. (2017). Luis Gutiérrez Soto en Sevilla. 1954-1965. Informes de la Construcción, 69(548): e226, doi: http://dx.doi.org/10.3989/ic.16.046.

Copyright: (C) 2017 CSIC. Licencia / License: Salvo indicación contraria, todos los contenidos de la edición electrónica de Informes de la Construcción se distribuyen bajo una licencia de uso y distribución Creative Commons Attribution License (CC BY) Spain 3.o. 


\section{EL LUGAR}

La obra de Gutiérrez Soto en la ciudad de Sevilla y dentro del ámbito residencial, se limita a tres inmuebles promovidos y construidos, entre 1954 y 1965, por la empresa inmobiliaria IMSA (Inmuebles Modernos S.A.) en la Plaza de Cuba. Actualmente numerados como 5,6 y 8 correspondientes en su día, a los números 5-6, 7-8 y 9-10, ocupan tres de los cuatro sectores circulares en los que se ordena la singular plaza. Un espacio urbano ideado como la gran puerta de ingreso al ensanche de Los Remedios, exedra apoyada sobre el cauce del río, abierta como ningún otro espacio de la ciudad, a una relación directa con el río y el casco histórico situado en la orilla contraria. Esta plaza, que vertebra el tráfico del puente de San Telmo, constituye la cabecera de la, por aquel entonces denominada, Gran Vía Principal del Ensanche hoy, Avenida de la República Argentina.

Un eje viario que a lo largo de los diversos proyectos que configuraron su definición actual (M. Sánchez Dalp. 1912 J. Talavera y Heredia 1917-23, S. Zuazo 1922-8 y F.G. Mercadal 1928-31) ostentó un alto grado de representatividad como gran conexión territorial hacia el Oeste, eje fundamental del nuevo ensanche y enlace entre el casco histórico y el Nuevo Ferial que habría de situarse, inicialmente, en su extremo occidental, completando el fondo del barrio y resolviendo el tránsito entre la ciudad y la vega inundable del Guadalquivir.

Plaza y Avenida, como estructuras principales del nuevo ensanche de Los Remedios, vendrían a configurarse a partir de la segunda mitad del s. XX en lugar natural de asentamiento de un tipo residencial desconocido en la ciudad, destinado a las clases más acomodadas y que podríamos definir como Vivienda Máxima.

Viviendas, cuyas superficies construidas superan los $200 \mathrm{~m}^{2}$ alcanzando, en el caso que nos ocupa, un rango comprendido entre $299 \mathrm{~m}^{2}$ y $459 \mathrm{~m}^{2}$, en las que el proyectista creará espacios capaces de construir una imagen del más alto estatus social, fachadas y ámbitos internos de gran exposición pública, integrados con estancias que garantizan el aislamiento y la privacidad de residentes y servicio, diseñadas y equipadas para lograr altos niveles de confort.

Viviendas en las que se conjugaban complejos programas de representación, estancia, descanso y servicio junto a circulaciones comunes y privadas, de residentes, invitados y servicio, en un intricado juego de articulaciones en el que Gutiérrez Soto había demostrado una extraordinaria habilidad.

Un tipo residencial que en Madrid y Barcelona poseía amplia y reconocida trayectoria, pero que en la Sevilla de 1954 resultaba absolutamente desconocido, tanto para los arquitectos locales como para los residentes que llegarían a ocuparlo, alojados hasta entonces en casas-patio de un casco histórico amenazado por inundaciones, con precarias condiciones de salubridad, escaso equipamiento y difícil accesibilidad.

\section{LOS PROYECTOS}

El proyecto del inmueble $\mathrm{n}^{0}$ 5-6, fechado en Noviembre de 1954 (licencia Marzo 1955, fin obra Enero 1957), hace mención a su pertenencia a «un proyecto general referente al conjunto de edificaciones» de la Plaza de Cuba, encargado por
IMSA en 1947. Un proyecto que se prolongaría en su tramitación debido a las diferentes interpretaciones que hacían la Academia de Bellas Artes y el Municipio. Mientras la primera, recomendaba no superar las siete plantas, la Oficina Técnica de Proyectos y Ejecuciones de la Sección de Ordenación Urbana consideraba que los dos edificios que flanqueaban el acceso a la Avenida debían incluir soportales, eliminar áticos retranqueados y presentar una altura de treinta metros $(\mathrm{Pb}+9)$, mientras que los otros dos no debían superar los diecinueve metros y medio $(\mathrm{Pb}+5)$.

Finalmente el Arquitecto Titular de la Oficina de Proyectos y Ejecuciones, daría viabilidad al proyecto inicialmente presentado considerando que respondía a las Ordenanzas Particulares del Ensanche. Así Gutiérrez Soto redactaría los proyectos, en sucesivas etapas, sobre tres de las cuatro manzanas, quedando la cuarta en manos de otros propietarios y otros equipos de arquitectos (Inmueble $\mathrm{n}^{0} 1$. Rafael de la $\mathrm{Hoz}$ y Gerardo Olivares, inmuebles $n^{0}$ 2, 3 y 4 Ricardo Abaurre y Luis Díaz del Río) (Figura 1).

El proyecto para el $n^{0} 5-6$, firmado junto a Antonio Corrales, comprendía un total de 29 viviendas, distribuidas en ocho plantas y ático sobre planta baja porticada en su frente a la Plaza de Cuba y sótano destinado a aparcamiento, instalaciones y trasteros. En la ejecución final las viviendas se reducirán a 27, al dedicar la planta baja a comercio e introducir los característicos soportales presentes en la Avenida que favorecían la integración urbana del inmueble al tiempo que revalorizaban la actuación y definían un plano noble para el tejido residencial.

El segundo proyecto, $\mathrm{n}^{0}$ 7-8 (con 27 viviendas y planta baja comercial) y el tercero, $\mathrm{n}^{0}$ 9-10 (con 36 viviendas y planta baja comercial) aparecen firmados en solitario en Diciembre de 1956 (licencia Abril 1957, fin obra Julio 1959) y Enero de 1962 (licencia Enero 1962, fin obra Octubre 1965) respectivamente.

Pese a presentarse los tres como documentos independientes y estar elaborados en fechas distintas, todos ellos inciden en la pertenencia a un proyecto global para la plaza. Un hecho que se hace evidente en los dos primeros, que mantendrán una unidad formal y compositiva en sus fachadas y en los modos de organización interna y ocupación, que el tercer inmueble abandonaría, para construirse desde parámetros muy diferentes, que romperían con esta armonía material y compositiva de las fachadas, introducirían viviendas de muy diversos tipos y eliminarían la rica volumetría que aportaban los patios abiertos.

\section{INMUEBLES 5-6 Y 7-8}

Los inmuebles 5-6 (Figura 2 Sup) y 7-8 (Figura 2 Inf) se proyectaron como piezas aparentemente simétricas conformando la nueva puerta al ensanche. Ambos responden a una misma implantación en la parcela que, con forma de sector circular de $25 \mathrm{~m}$ de fondo, fueron segregadas de sus respectivas manzanas mediante la inclusión de una vía de servicio. En palabras del propio Luis Gutiérrez Soto:

«Después de varios tanteos se ha llegado al proyecto actual de tres viviendas por planta, con dos escaleras mixtas de señores y de servicio y dos patios abiertos a la calle posterior. La solución ofrece varias ventajas; se suprimen los 

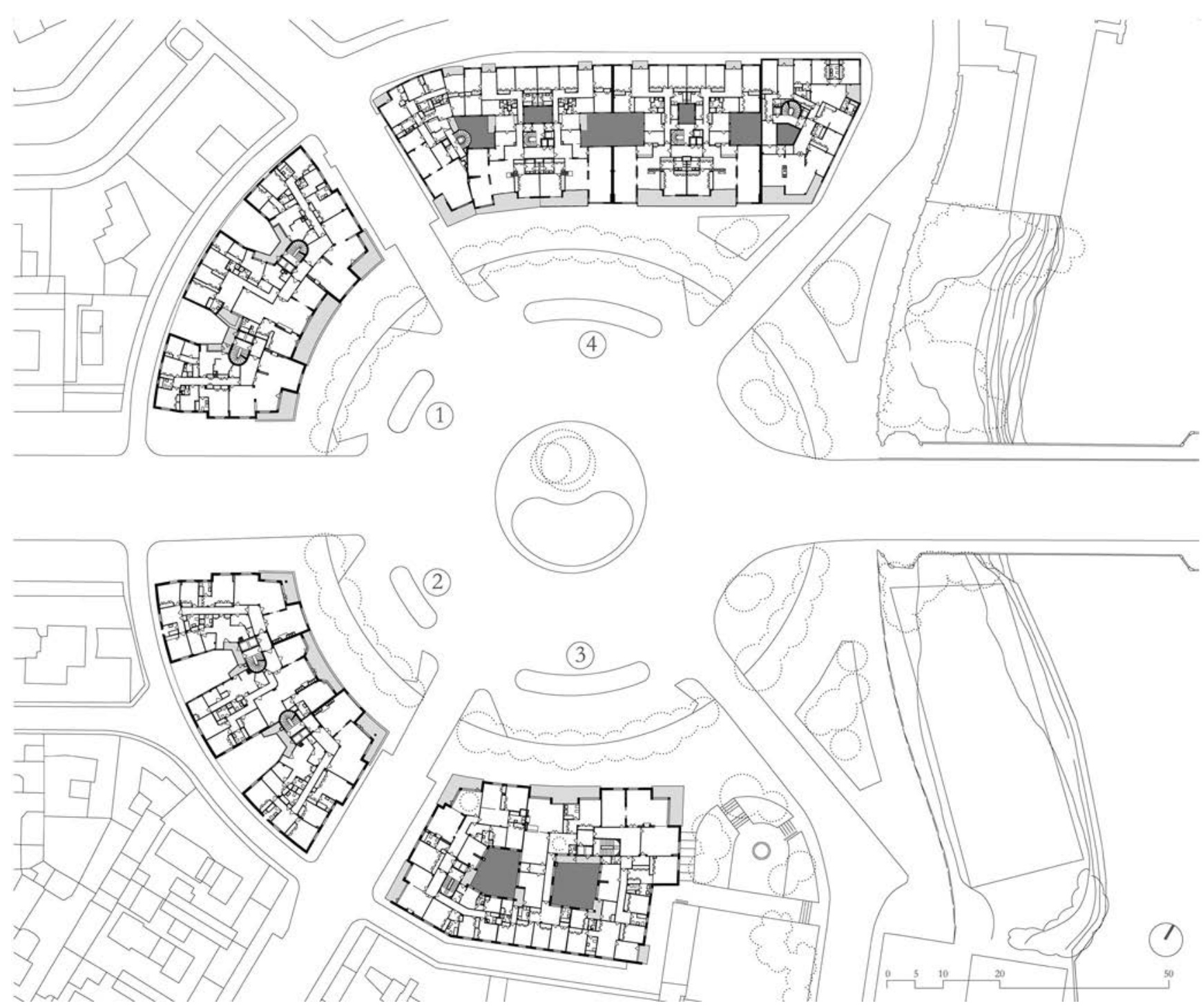

Figura 1. Planta General de la plaza de Cuba 1965. Escala 1:1.200

(1) Inmueble 5-6. (2) Inmueble 7-8. (3). Inmueble 9-10. (4) Inmuebles 1, 2, 3 y 4. Dibujos del autor.

patios cerrados y en su lugar se proyecta un patio abierto a la calle posterior al cual dan únicamente huecos de servicio; sin embargo las mamparas de cristal prensado de las terrazas tendederos impiden que el mal aspecto de estos patios quede manifiesto». (Gutiérrez Soto L., Extracto Memoria pag. 1 Expte COAS no 41457-c879).

Su estructura se proyectó de hormigón, vigas de canto y forjados unidireccionales y cimentación con zapatas aisladas y muro de sótano perimetral. Los cuerpos de edificación extremos, en ambos proyectos, presentan tres crujías, siendo la dimensión de la central variable, desde 1,6 m en el entronque con el cuerpo de fachada, hasta los 4,55 $\mathrm{m}$ en el extremo del ala. Sin embargo el cuerpo central sufrirá modificaciones de un proyecto a otro, presentando inicialmente una solución de tres crujías de anchos variables, y posteriormente dos de $5,30 \mathrm{~m}$.

Esta modificación está vinculada con el giro de $180^{\circ}$ que presentan los núcleos verticales entre un proyecto y otro, la reducción que experimenta el cuerpo central y la consiguiente ampliación de los patios abiertos a fachada. En ambos proyectos, el cuerpo de fachada a la Plaza de Cuba se proyecta de manera similar; en los fondos de los patios se sitúan las cajas de escalera.

Apoyada en éstas, una primera crujía interior (2,40 m), coincidente con los vestíbulos de viviendas, y una segunda crujía mayor $(5,00 \mathrm{~m})$ de salones y despachos, finalmente, losas voladas resolverán la fachada, permitiendo el libre retranqueo del plano de cerramiento y la aparición de las terrazas con 2,80 m de fondo máximo.

La solución de la terraza de esquina es distinta en cada proyecto, mientras en el primero se proyectaron con el pilar oculto en el cerramiento, en el segundo, el pilar se proyectó aislado reduciendo el vuelo y los esfuerzos estructurales.

Las tres amplias viviendas por planta, completamente exteriores, respondían a dos variantes de un mismo tipo con superficies construidas comprendidas entre 341 y $365 \mathrm{~m}^{2}$ en el inmueble $n^{0} 5^{-6}$ y entre 299 y $320 \mathrm{~m}^{2}$ en el inmueble $\mathrm{n}^{0} 7-8$.

La primera variante, situada en los cuerpos extremos, presenta un programa similar en ambos proyectos; áreas de representación compuestas por un amplio vestíbulo conectado 

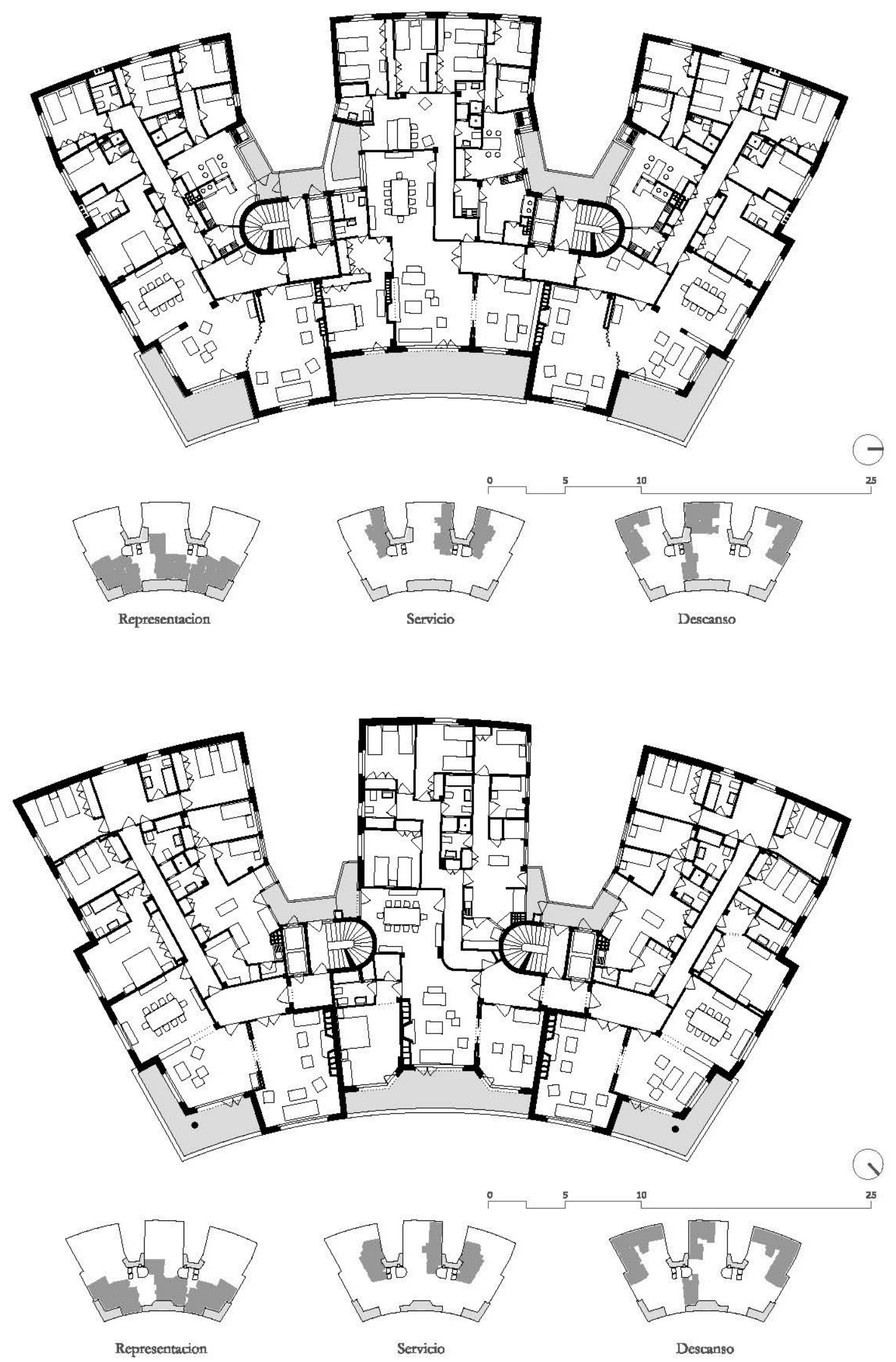

Figura 2. Superior - Planta Tipo y esquemas de uso. Inmueble $\mathrm{n}^{0} 5-6$. Inferior - Planta Tipo y esquemas de uso. Inmueble $\mathrm{n}^{0} 7-8$ Escala 1:400. Dibujos del autor.

con despacho y salón, situado en el vértice de la planta y en contacto directo con las terrazas más un comedor, abierto al salón y con acceso secundario desde el pasillo general de la vivienda.
La estructura espacial de estas piezas resulta ambigua, pues los descuelgues de las jácenas y las imponentes molduras de escayola, empleadas para decorar y ocultar la iluminación, definen una segregación espacial clara distorsionada por la 
hábil disposición de puertas correderas junto a planos de estanterías que favorecen la conexión visual.

Las áreas de descanso se componen de un dormitorio principal, con baño, y tres dormitorios infantiles servidos por dos núcleos de aseo. Entre el inmueble $\mathrm{n}^{\mathrm{0}} 5-6$ y el 7-8 se aprecian diferencias en la manera de disponer las piezas, la dotación de los núcleos húmedos y la aparición del cuarto de juegos.

Mientras en el primer proyecto el dormitorio principal dispone de baño incorporado, dos dormitorios infantiles cuentan con baño común y el tercero dispone de aseo con ducha incorporado, en el segundo proyecto el dormitorio principal dispone además de un espacio vestidor, como vestíbulo de la alcoba y los dormitorios infantiles cuentan con dos baños completos de uso común además de una nueva sala, destinada a cuarto de juegos.

Los espacios del servicio son similares en ambos proyectos: dos dormitorios, aseo con ducha, cocina, oficio, alacena y terraza tendedero como punto de ingreso desde el núcleo vertical. Sin embargo, en el segundo proyecto se logran compactar la superficie y optimizar las instalaciones, frente a la dispersión apreciable en el primero se advierte ahora, un agrupamiento de los núcleos húmedos, una mejor disposición de las ventilaciones de cocina y una reducción de la superficie de los dormitorios que liberan la fachada posterior.

La vivienda situada en el cuerpo central, comparte el programa de las anteriores incorporando una variación importante relacionada con el dormitorio principal.

En ambos proyectos, ésta pieza es segregada y denominada «apartamento» pasando a ocupar una posición preferente en la fachada a la Plaza de Cuba.

Esta nueva ubicación dificultará la privacidad de la pieza, que será difícilmente resuelta incorporando un pequeño vestíbulo previo que, entre el proyecto de 1954 y el de 1956, reducirá notable su tamaño siendo, en el primer caso, generosamente diseñada como vestidor, mientras que en el segundo apenas alcanza a configurarse como espacio independiente.

Pese a mantener una composición aparentemente simétrica, Gutiérrez Soto abandona el lenguaje clásico y cualquier am- bición por recrear una idea de monumentalidad en las fachadas, para presentar cierta imagen de modernidad a través de una revisión de la tradición (Figuras 3, 4 y 5).

Podríamos decir que ambos proyectos se encuentran en un momento de transición entre su «período monumental», dominado por un lenguaje clásico y hasta cierto punto nostálgico, y un período de mayor libertad compositiva, que Miguel A. Baldellou denominó su «estilo maduro» (4)

Ambos edificios se presentan como prismas de revoco blanco avitolado (en referencia a la arquitectura local y al Convento de los Remedios) sobre una planta baja porticada, en la que destaca el diverso tratamiento que adopta el soportal a lo largo de sus tres fachadas principales; claramente definido por imponentes pilares y dinteles revestidos en piedra caliza de irregular y cuidado despiece a la Avenida, ausente en la fachada opuesta y, en forma de columnata, hacia la Plaza de Cuba. El volumen blanco, salpicado de ventanas, cuyos recercados, inicialmente previstos en azulejo local, serían ejecutados con generosas secciones de mármol travertino, queda orientado claramente hacia la plaza, siendo esta fachada la que concentra los mayores recursos formales y compositivos.

Las terrazas, a levante, buscan las vistas sobre la plaza, la ciudad y el río. Sus característicos fondos quebrados, siempre presentes en la obra de Gutiérrez Soto, y sus acabados recuerdan a las, por él proyectadas en 1951 para el inmueble de c/Juan Bravo c/v Velázquez o a las del edificio de Paseo de Rosales c/v Rey Francisco, de 1952 (4). Vuelos ligeros de los tableros del forjado, sin petos de obra que impidan la visión, una mirada matizada por el leve filtro de las barandillas, la vegetación y los toldos. «Terrazas-jardín» como las denominaría el propio autor, que al quebrar y retranquear su plano interior se transforman en amplias estancias abiertas a la ciudad, jardines colgantes que, a la vez que protegen del soleamiento directo, dilatan el espacio interior de la vivienda intentando apropiarse de la plaza.

Gutiérrez Soto utiliza así formas, materiales y texturas para construir una sobria escena entroncada con la memoria cultural de los futuros residentes de estas viviendas, levantadas en el vacío de la periferia que buscan, no sólo una imagen representativa de su estatus social, sino un confort imposible de alcanzar en el viejo casco histórico.

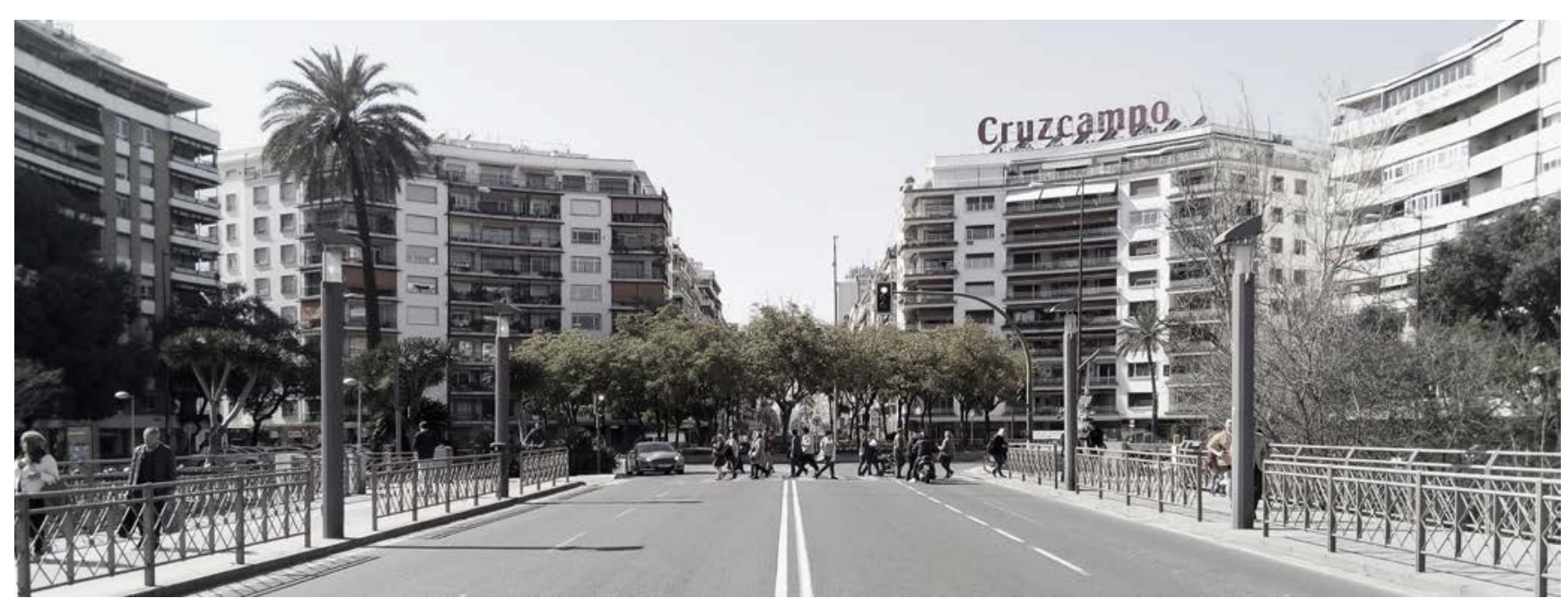

Figura. 3. Vista General de la Plaza de Cuba. Izquierda Inmueble n ${ }^{0}$ 5-6. Derecha Inmueble no 7-8. Fotografía del autor. 

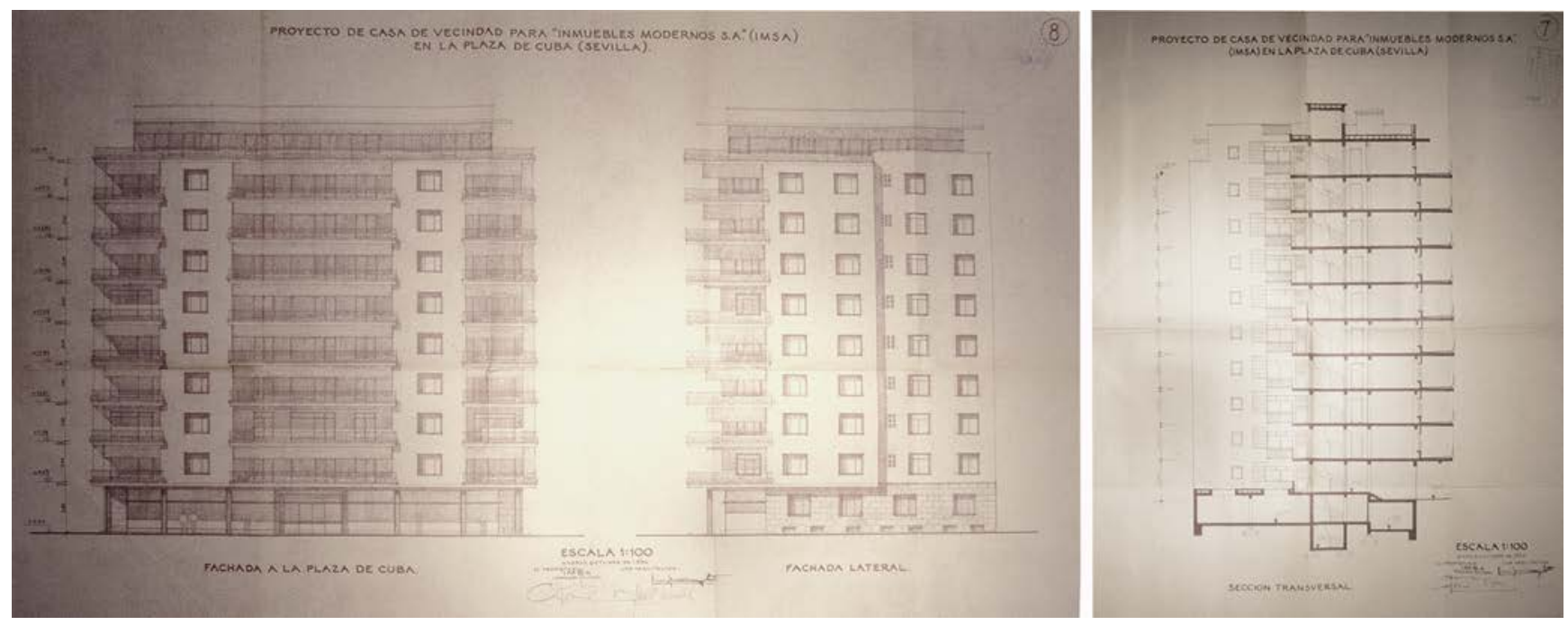

Figura 4. Alzados y Sección del Proyecto para el Inmueble no 5-6. Fuente A. V. COA Sevilla. Expt. № 45457-c879.

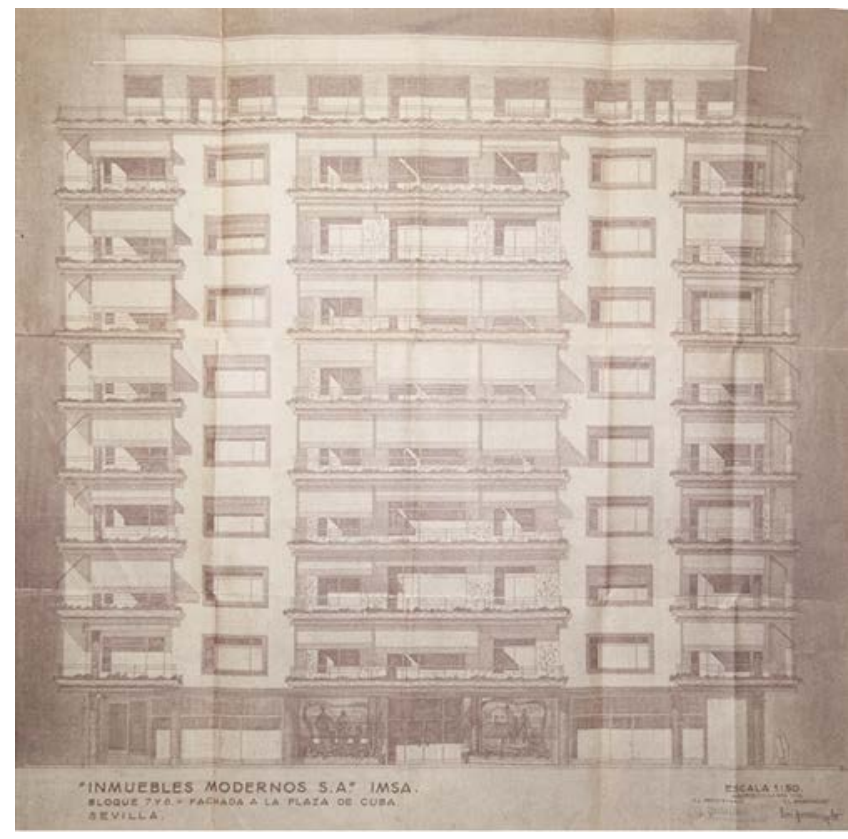

Figura 5. Alzado del Proyecto para el Inmueble $\mathrm{n}^{0}$ 7-8. Fuente A. V. COA Sevilla Expt n ${ }^{\circ} 48383$.

Las memorias de los proyectos describen, de forma muy elemental, calidades y equipamientos; suelos de madera en estancias familiares y salones, mármol en espacios de circulación general, baldosín en terrazas y espacios de servicio, luz eléctrica en falsos techos, cajeados y molduras, panelados con lamas de madera y carpinterías de bronce en los portales, murales cerámicos realizados por artistas y artesanos en portales de ingreso, instalaciones centralizadas de calefacción por radiadores y agua caliente sanitaria, chimeneas, elementos foráneos y extraños en esta ciudad pero necesarios como imagen de distinción, abundantes espacios de almacenamiento en el interior de la vivienda, cuartos para carritos en el portal y trasteros, almacenes y aparcamiento en sótano, para 13 vehículos en el primer proyecto y 19 en el segundo. Elementos, todos ellos, que describen niveles de equipamiento absolutamente novedosos en la Sevilla de 1954.

Los accesos (Figuras 6, 7 y 8) de ambos proyectos construyen un ritual heredero del s. XIX que, en el caso sevillano, sólo se alterará a partir del año 1961, cuando el equipo Abaurre-Díaz del Río introduzca una variante en su proyecto para el $n^{0} 2$ de la Plaza de Cuba que eliminará las diferentes cotas y simplificará las relaciones espaciales, en un ingreso acorde con el cambio social experimentado en la España del Desarrollismo.

Aquí reconocemos un amplio frente acristalado protegido con rejas metálicas, destacado en la fachada y flanqueado por murales cerámicos, tras él y separado del siguiente ámbito espacial por unos peldaños y un cortaviento, encontramos el zaguán, espacio que será compartido por residentes, visitas y personal de servicio. En este punto la circulación de servicio desciende para alcanzar, en sótano, los montacargas y escaleras, mientras que visitantes y residentes ascienden varios peldaños para acceder a una sala de espera o continuar el ascenso hacia sendos vestíbulos laterales, previos a los ascensores, que conducen a las viviendas. Se trata de una secuencia espacial que recrea la estratificación social, al tiempo que construye espacios adaptados a los distintos usuarios.

Los núcleos verticales se disponen girados $180^{\circ}$ entre un proyecto y el otro, cuestión que repercutirá en la dimensión de la vivienda central y los patios. No obstante su trascendencia se halla en su configuración interna y posterior repercusión en el desarrollo de esta tipología en Sevilla. Para ellos Gutiérrez Soto emplea una solución similar a la proyectada en Madrid en las viviendas de c/ Vallehermoso, R. de San Pedro y Arapiles de 1954 (4). Pero en estos proyectos sevillanos ensayará, optimizará y consolidará la solución, permitiendo que el ascensor de servicio y el principal compartan un único espacio.

Hasta entonces los núcleos por él diseñados disponían los ascensores principales alejados de los montacargas, construyendo complejas articulaciones en las que habitualmente se duplicaban los núcleos.

La solución planteada ahora (Figura 9), sitúa los ascensores y montacargas con accesos enfrentados, desde los vestíbulos principales, los de residentes y visitas y, desde galerías de servicio, los montacargas. La escalera, compartida y en perpendicular a la caja de ascensores, tendrá acceso desde ambos lados. Esta organización facilita la distribución de las viviendas garantizando la separación total de circulaciones. 

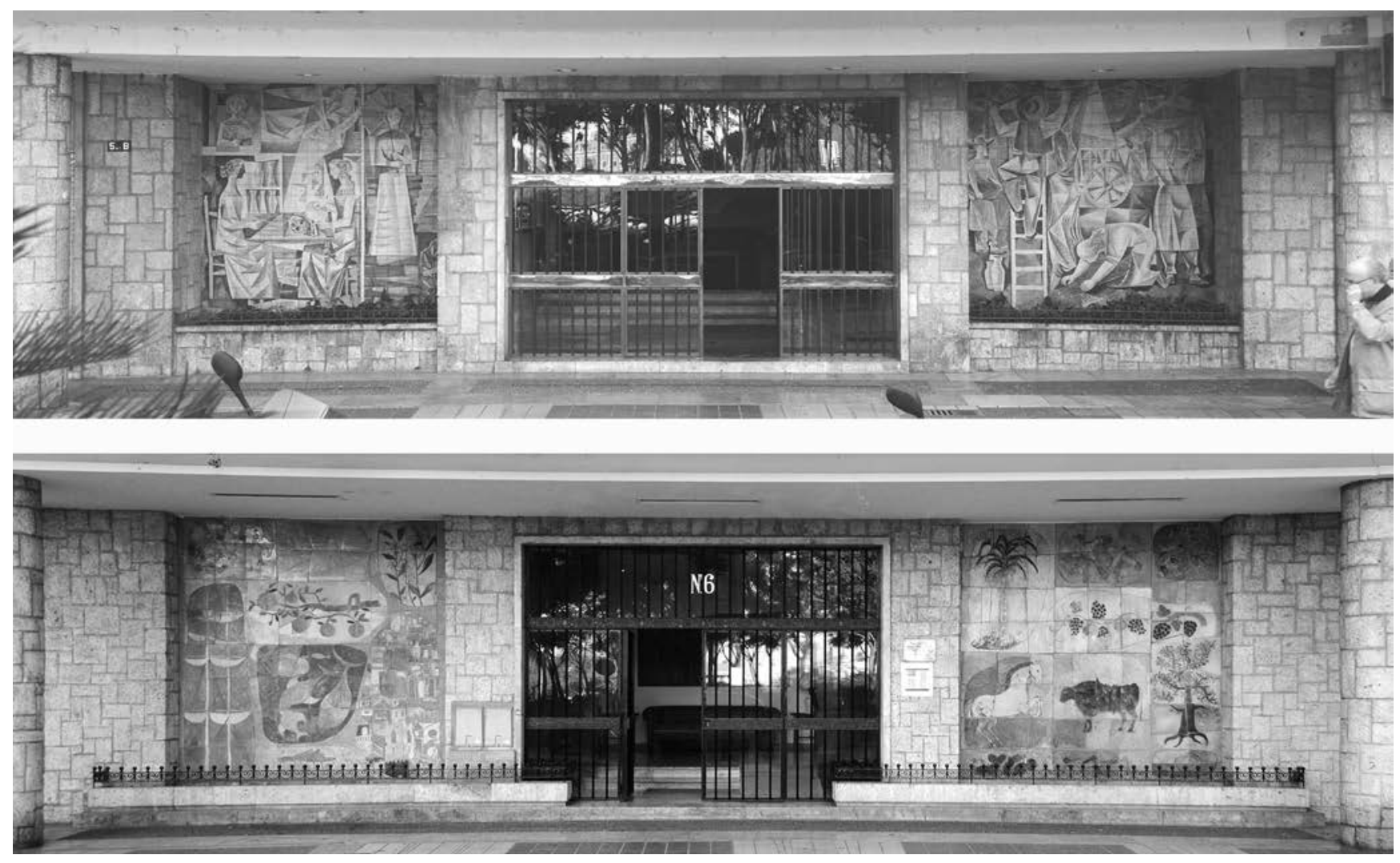

Figura 6. Frentes de Portal. Superior Inmueble $n^{0} 5-6$. Inferios $n^{0} 7-8$. Fotografia del autor.
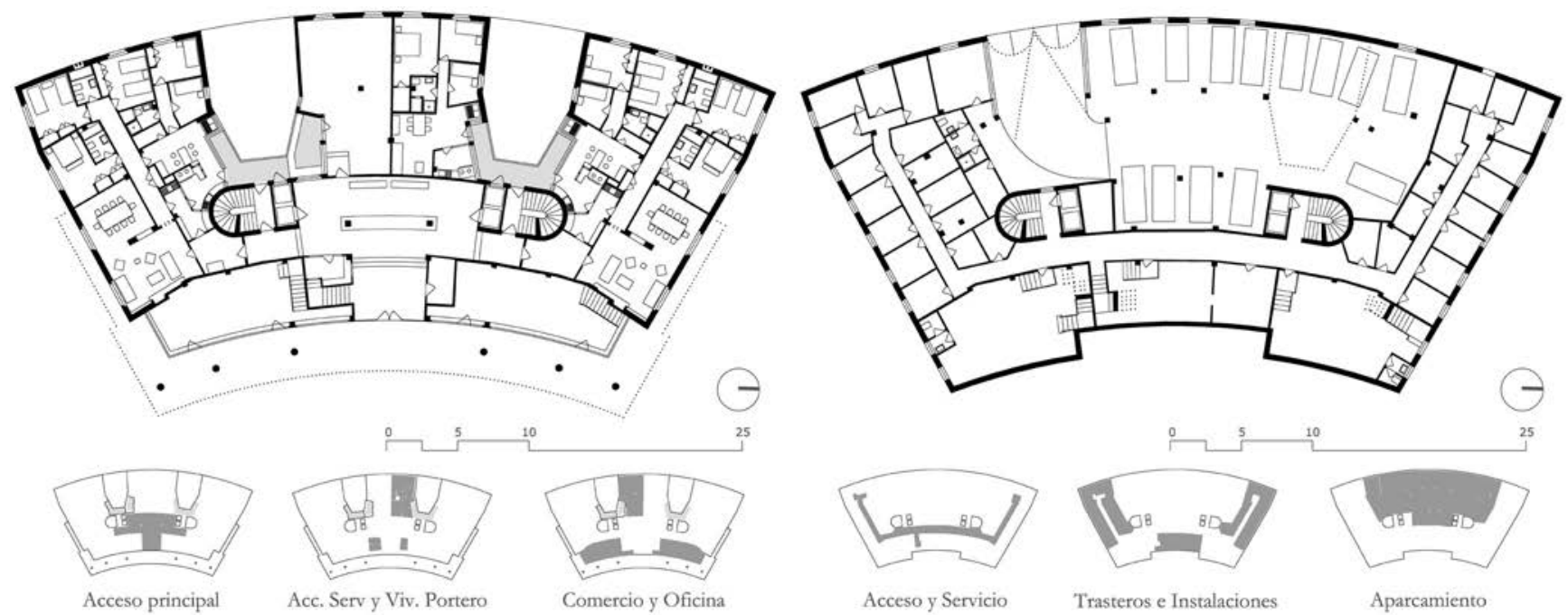

Figura 7. Planta Baja y Sótano y esquemas de uso. Inmueble n ${ }^{0}$ 5-6. Escala 1:60o. Dibujo del autor.

Dentro de la extensa obra de Gutiérrez Soto debemos remontarnos al proyecto de viviendas en la calle Miguel Ángel 2-6 c/v Rafael Calvo 40 de 1935 (6), para encontrar un recurso, en cierta forma, similar al proyectado en Sevilla.

\section{INMUEBLE 9-10}

«Este bloque de casas es el tercero a construir, propiedad de la citada Sociedad, en el conjunto urbano que ha de formar la Plaza de Cuba, cuyo proyecto fue redactado en su totalidad, y a éste, seguirán las edificaciones restantes hasta completar esta zona de la Gran Vía Sevillana.» (Gutiérrez Soto L., Extracto de la memoria pag.1 Expediente COAS nº 64783.84_1212).
Pese a las intenciones enunciadas ésta sería la última intervención de Gutiérrez Soto en la Plaza de Cuba. Un proyecto inserto plenamente en su «estilo maduro» en el que abandona cualquier intento de aproximación estética al imaginario colectivo sevillano, incorporando recursos formales y materiales que lo identifican con una cierta imagen de marca, propia de esta etapa biográfica.

Fábricas de ladrillo visto, aplacados pétreos que revisten los cantos de forjado y falsos techos previstos en las terrazas, resultando vuelos más pesados, frente a las ligeras losas proyectadas en los inmuebles anteriores. Vuelos que dibujan con mayor énfasis las aristas del volumen, haciéndolo más reconocible, en contraposición a la disolución de las aristas 


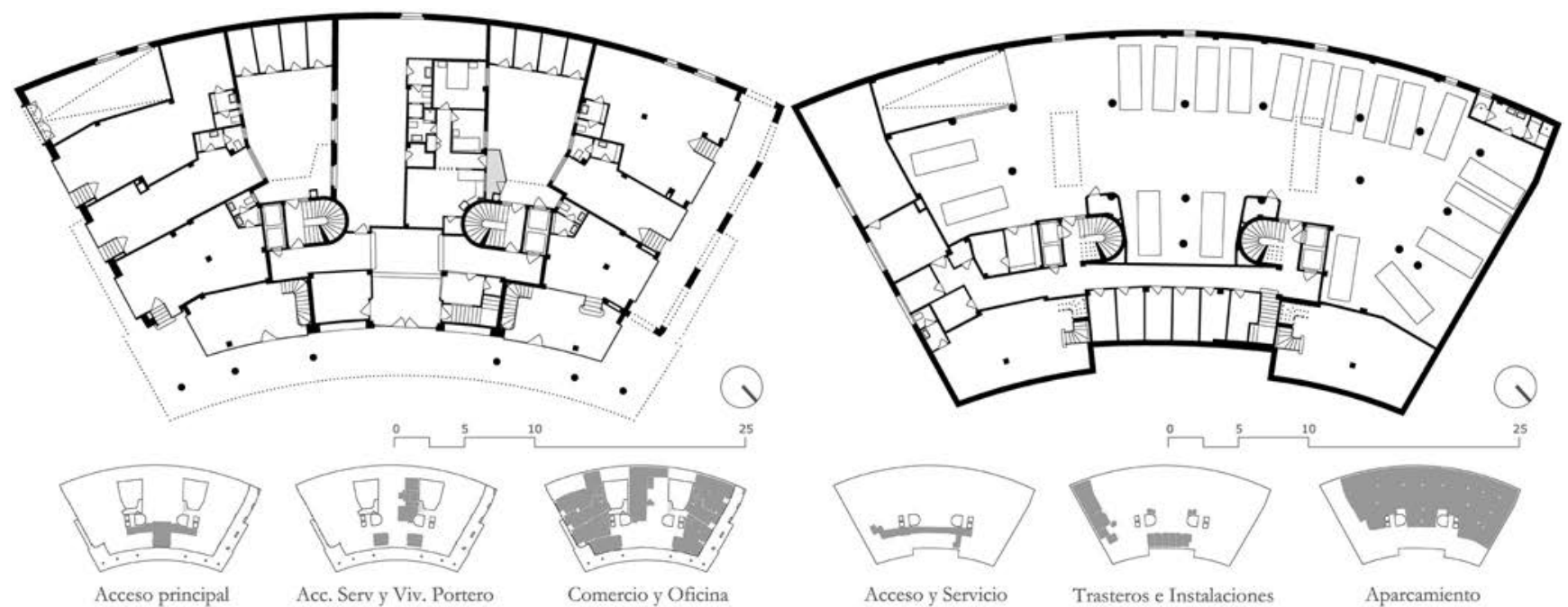

Figura 8. Planta Baja y Sótano y esquemas de uso. Inmueble no 7-8. Escala 1:60o. Dibujo del autor.

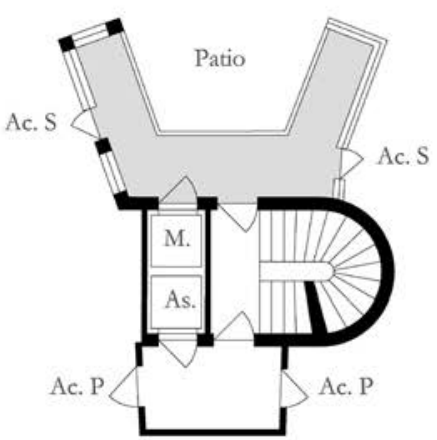

(1)

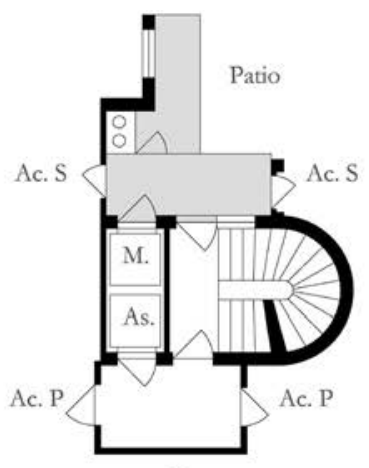

(2)

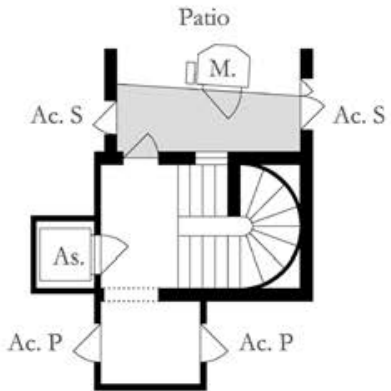

(3)

$\begin{array}{llll}\text { As.P Acceso Principal } & \text { Ac.S } & \text { Acceso de Servicio } \\ \text { As } & \text { Ascensor Principal o "de señores" } & \text { M } & \text { Montacargas de Servicio }\end{array}$

Figura 9. Núcleos de Comunicaciones Verticales (1) Plaza de Cuba 5-6, 1954 (2) Calle Vallehermoso, R. San Pedro y Arapiles, 1954 (3) Calle Miguel Ángel 2-6 c/v Rafael Calvo 40. 1935. Escala 1:250. Dibujo del autor.

que caracterizaba los proyectos anteriores. Los amplísimos huecos, de proporción rectangular y posición horizontal, proyectados anteriormente y que, junto con las terrazas, dibujan bandas horizontales que dominaban la composición, son ahora sustituidos por parejas de huecos verticales, cuyos petos y dinteles aplacados introducen un nuevo orden vertical en la composición que, en cierta medida, resulta ajeno a la plaza (Figura 10).

Los filtros que componen el plano exterior de las terrazas, incorporan amplios maceteros de colores, barandillas conformadas con tubos de acero y esbeltos pilarillos que sirven de soporte para los toldos. Por encima de estos, aparecerán los brise-soleils, que ya habían sido tímidamente introducidos en el inmueble $\mathrm{n}^{\mathrm{o}} 7-8$, componiendo un conjunto que será objeto de continua investigación y transformación a lo largo de esta etapa biográfica.

Esta otra manera de hacer, más segura en su propia afirmación estilística, que evita cualquier contextualización, no favorece la aceptación e integración de la obra, un hecho constatado por la catalogación de PGOU del resto de inmuebles que conforman la Plaza de Cuba basada, precisamente, en la unidad formal y compositiva que deja esta obra excluida de cualquier grado de protección.
Su planta (Figura 11) ordena cuatro viviendas de muy diversa superficie $\left(459 / 371 / 280 / 133 \mathrm{~m}^{2}\right)$ en torno a dos patios interiores que resuelven la iluminación y ventilación de sus áreas de servicio, mientras que las áreas de representación y descanso ocupan el perímetro de parcela.

En planta baja se proyectan dos pequeñas viviendas de servicio, los portales de ingreso y locales comerciales. En sótano, espacios vinculados al comercio, trasteros y aparcamiento.

Pese a que las plazas de aparcamiento no aparecen dibujadas, la regularidad de la estructura permite adivinar una mayor preocupación por aumentar el rendimiento hasta alcanzar las 25 referidas en memoria.

En los accesos se mantienen los mismos materiales, madera y piedra, pero se modifica su presentación. Frente a la solemnidad que desprendían las lamas de madera empleadas anteriormente, los paneles contrachapados utilizados ahora aportan una imagen de modernidad.

Los controles de acceso, diseñados anteriormente como cabinas cerradas, se construirán ahora como hornacinas abiertas 


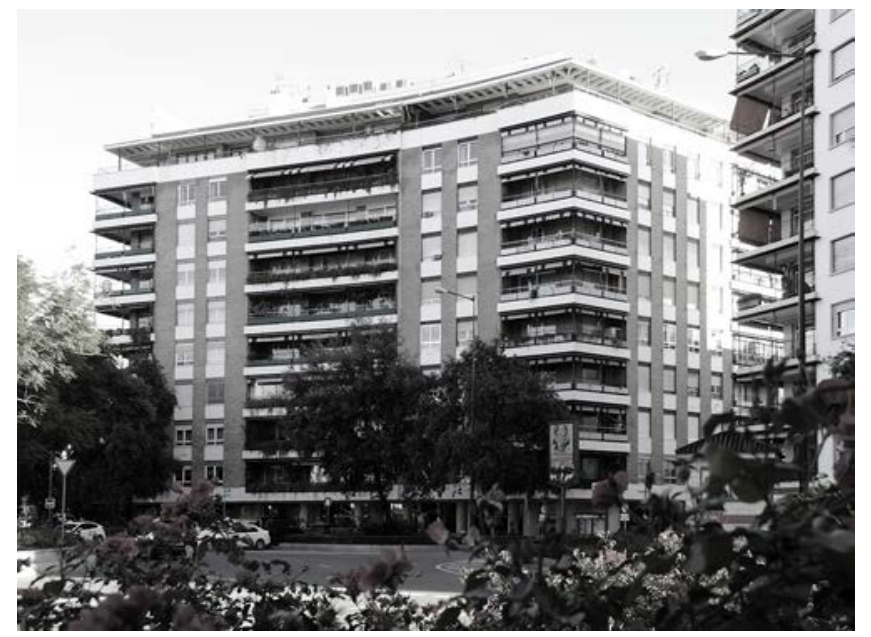

Figura 10. Vista del Inmueble $\mathrm{n}^{0}$ 9-10. Fotografía del autor.

al portal, que se concibe como espacio unitario, sin la anterior segregación funcional y social producida por la existencia de niveles diversos. (Figura 12).

En la mayor de las viviendas, que ocupa íntegramente el sector oriental del inmueble, encontramos tres variaciones respecto a los tipos anteriores que permiten apreciar cierta evolución.

En primer lugar la chimenea pasa del despacho al salón, en un movimiento, aparentemente irrelevante, que debe vincularse al cambio de significado de ésta de imagen de estatus social a icono del confort en el hogar. Cuestión ésta relacionada con el cambio social y la aparición de un nuevo tipo de residente que busca, ante todo, comodidad. Desde un punto de vista disciplinar, este cambio podría relacionarse con los contactos de la arquitectura española con la americana y especialmente con la obra de R. Neutra.

Un segundo cambio afecta al comedor, que se abre al vestíbulo, transformándose en lugar de recepción directa, cuando en los tipos anteriores requería del paso previo por la sala de estar.

La búsqueda del confort puede apreciase igualmente en la dotación y el detalle con que se proyectan los núcleos húmedos; aparece por primera vez el aseo de cortesía y el baño principal, se proyecta con espacios diferenciados para lavabos y piezas de baño.

También la organización del área de descanso cambia. Se distinguen ahora tres tipos de dormitorios; «el apartamento», los infantiles, situados en torno al cuarto de juegos y un tercer tipo, con aseo compartido, situado a caballo entre los anteriores, probablemente destinado a los hijos de mayor edad, familiares mayores o invitados. Se producen en definitiva clasificaciones y segregaciones espaciales que favorecen el mejor uso de la vivienda, y la dotan de una mayor comodidad y privacidad.

\section{CONCLUSIÓN. IMPRONTA TIPOLÓGICA}

La aparición de Viviendas Máximas en Sevilla se remonta a la segunda mitad de la década de 1950 y se circunscribe a un área muy concreta del barrio de Los Remedios: Pla-
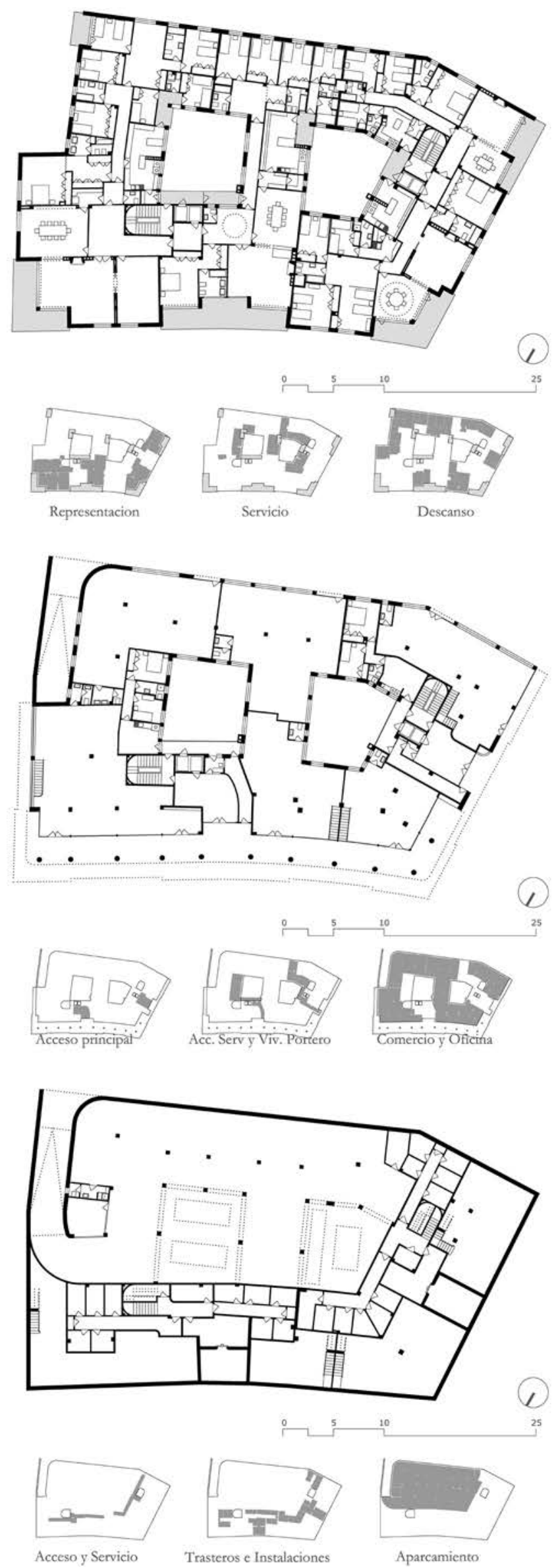

Figura 11. Inmueble $\mathrm{n}^{\mathrm{o}}$ 9-10. Superior. Planta Tipo y esquemas de uso. Centro. Planta Baja y esquemas de uso. Inferior. Planta Sótano y esquemas de uso. Escala 1:60o. Dibujos del autor. 

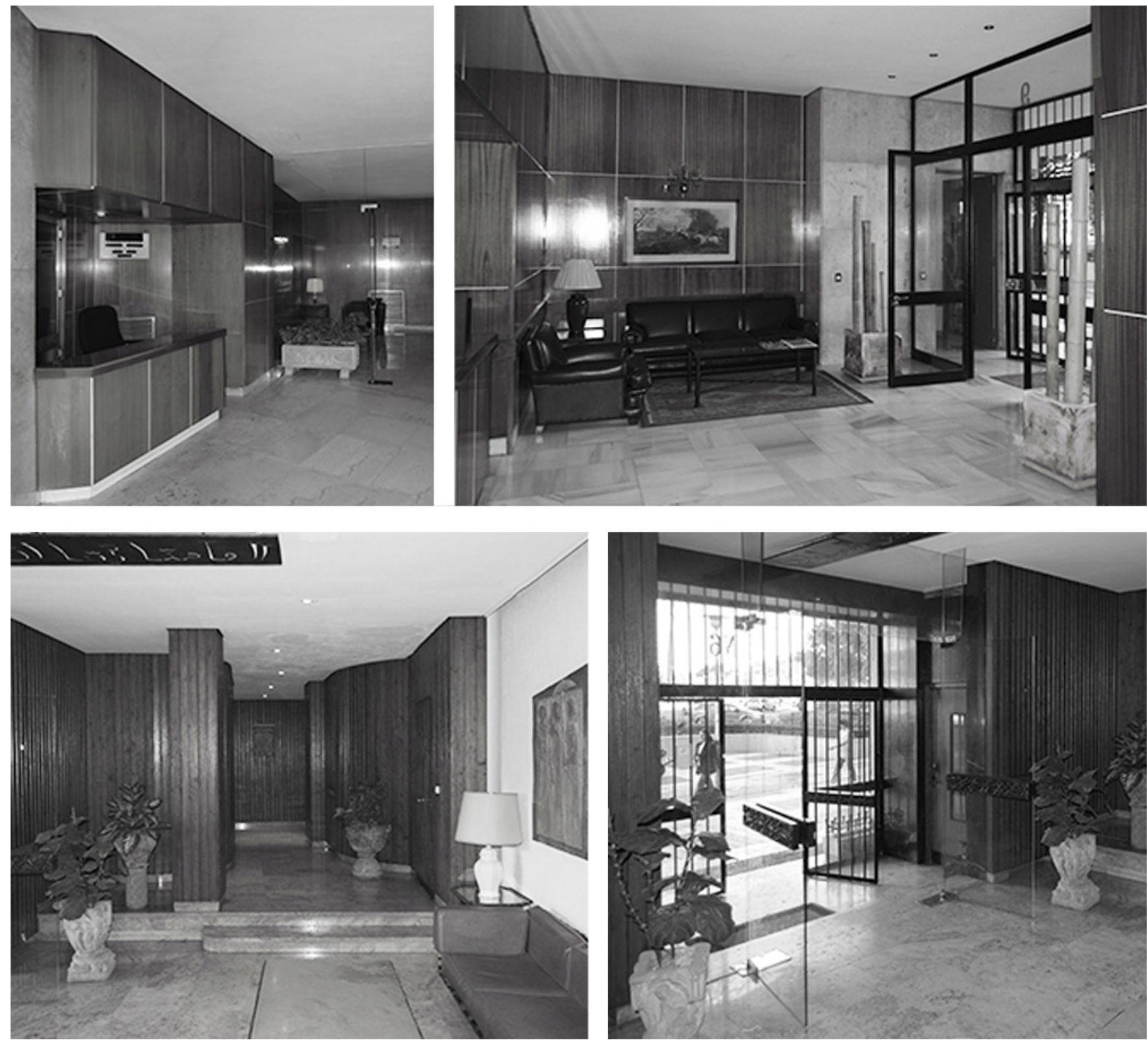

Figura 12. Superior Portal Inmueble $n^{0}$ 9-10 Inferior. Portal Inmueble $n^{0}$ 7-8. Fotografía del autor.

za de Cuba y Avda. República Argentina, donde su presencia alcanza una densidad del 78,57\% (44 de 56 inmuebles contienen viviendas con superficie construida superior a $200 \mathrm{~m}^{2}$ ), mientras que su distribución en el resto del barrio representa el $2 \%$ (17 de 855 inmuebles). Fuera de esta área encontramos ejemplos aislados en los barrios del Porvenir, Huerta de la Salud y Nervión, que no alcanzan, ni por sus dimensiones ni por su densidad, la trascendencia de este singular eje urbano.

Luis Gutiérrez Soto sería el encargado de proyectar la primera actuación en 1954, desde entonces la implantación de este tipo residencial a lo largo del eje se prolongará hasta 1984 .

Entre 1954 y 1965 se producirán los tipos de mayor dimensión y complejidad. Fernando Barquín, Ricardo Espaiu, José Manuel Benjumea y muy especialmente el Ricardo Abaurre y Luis Díaz del Río, serán los arquitectos afincados en Sevilla que participen en estos proyectos. Proyectos en los que puede reconocerse la herencia que la obra de Gutiérrez Soto dejó en esta ciudad.

La concepción organizativa tripartita de la vivienda, cuestión que hoy día resulta perfectamente asumida por arquitectos y usuarios, no lo era tanto en la Sevilla de 1954, en la que los modelos tipológicos derivaban de la tradición local, la casapatio, o de organizaciones importadas de los primeros ejemplos del ensanche madrileño. Un claro ejemplo de esa otra manera de hacer serán los inmuebles $n^{0} 9$ y 11 de la Avda de la República Argentina (Figura 13), primeros inmuebles de esta tipología proyectados por un arquitecto local, José Manuel Benjumea Vázquez en 1955.

Según Daniel Rincón de la Vega (5) la vivienda de gran dimensión del primer tercio de s. XX madrileño puede considerase heredera del siglo precedente. En ella se mantiene una organización compleja de pequeñas estancias dispuestas a lo largo de extensos pasillos, surgidos de la posición extrema que ocupan las dos cajas de escaleras, una principal situada 

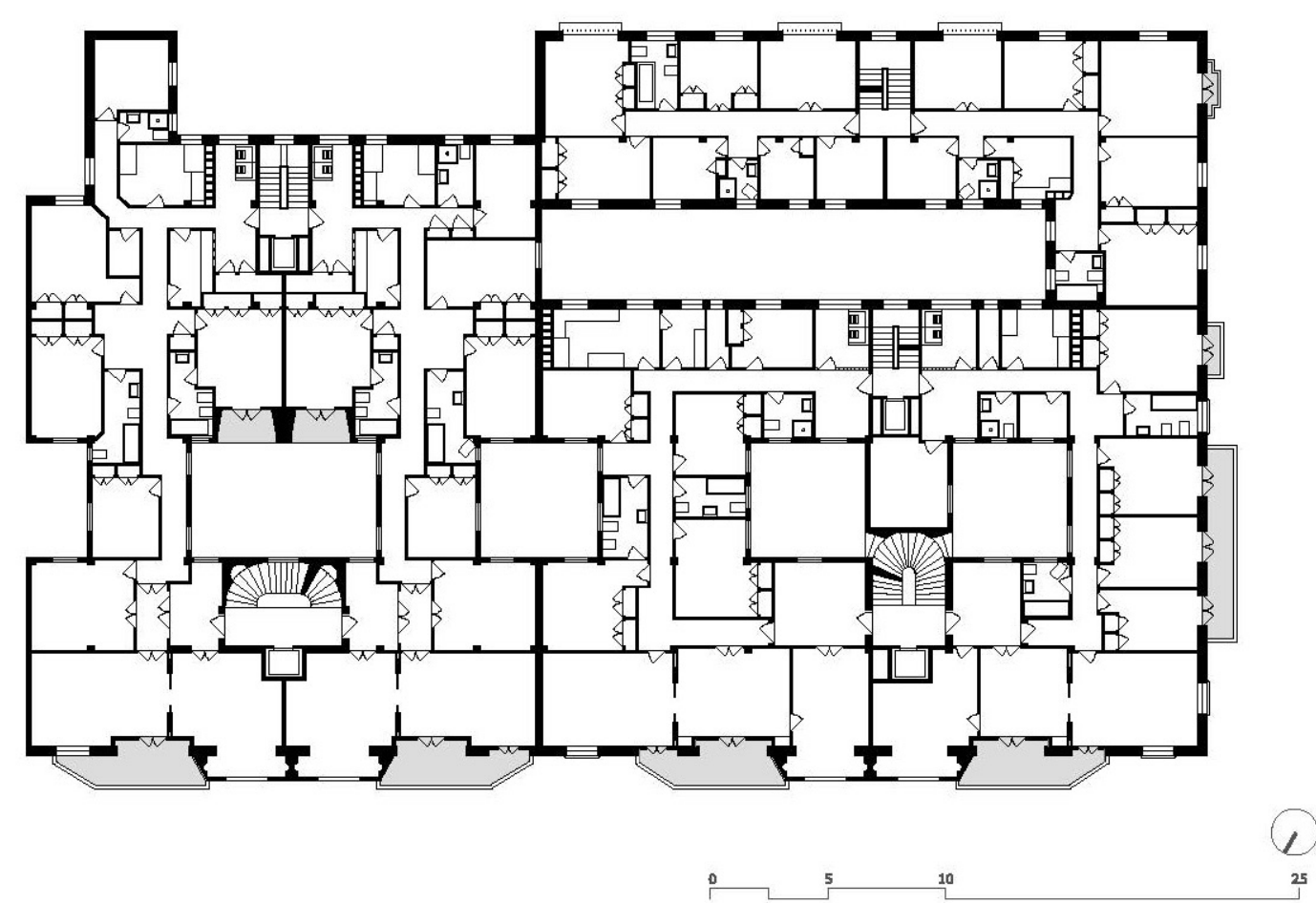

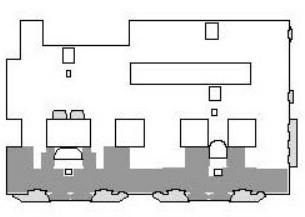

Representacion

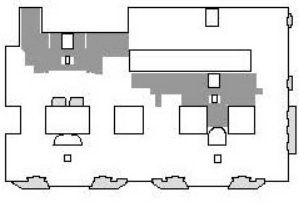

Servicio

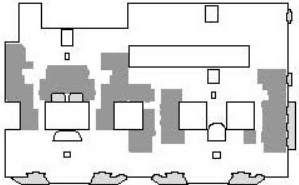

Descanso

Figura 13. Planta Tipo y esquenas de uso. Inmueble nº 9-11 Avda. República Argentina. Manuel Benumea Vázquez. Escala 1:400. Dibujo del autor.

en segunda o tercera crujía, y otra de servicio situada en el extremo opuesto de la planta.

La distribución de estancias respondería a una estructura de seis zonas enunciadas por Enrique María Repullés en su discurso de ingreso en la Real Academia de Bellas Artes de San Fernando «La casa-habitación moderna desde el punto de vista artístico». Zonas caracterizadas por diversos grados de privacidad y por su vinculación a usos concretos que determinaban su dimensión y posición en la vivienda: negocios, fiestas y reuniones, salas familiares, estancias privadas, dormitorios para el servicio y dependencias para el servicio.

Una sistematización ésta que, asumiendo cierta evolución, podría permitir una lectura del proyecto de José Manuel Benjumea en Sevilla, según la cual se reconocerían cinco de las seis zonas enunciadas: las piezas de representación, vestíbulo principal, despacho, distribuidor, salón y comedor, comprenderían dos de las zonas definidas por Repullés: negocios y fiestas y reuniones. Los dormitorios del servicio y todas las dependencias anexas se reconocen dispuestas en el extremo más alejado y profundo de la planta, a lo largo del pasillo, siguiendo la lógica decimonónica y provocando servidumbres de paso en el área de dormitorios familiares que ocupa el sector central de la planta.

Se trata de una organización muy alejada de la propuesta por Gutiérrez Soto, en la que el área de servicio se proyecta en el centro de gravedad de la planta, compactando su superficie y resolviendo de forma autónoma todas sus circulaciones internas, resultando un área perfectamente segregada del resto de la vivienda, con la que compartiría pocos y controlados puntos de conexión.

Este nuevo esquema sería rápidamente adoptado por todos los arquitectos locales. Dentro del eje Plaza de Cuba - Avda. República Argentina, todos los proyectos lo utilizarán salvo el anteriormente descrito y los inmuebles $\mathrm{n}^{0} 16,18,20$ proyectados por Fernando Barquín y Ricardo Espiau en 1954-55, que puede interpretarse como un momento de transición.

Los proyectos de Gutiérrez Soto dibujarán también un nuevo marco de referencia programático y funcional del área de descanso. Así su propuesta bi-nuclear, en la que el dormitorio principal se proyecta como «apartamento» y el cuarto de juegos actúa como elemento articulador de los dormitorios infantiles, será igualmente introducida en los siguientes proyectos de arquitectos locales.

Especialmente interesante será la solución, antes descrita, del núcleo de comunicaciones, adoptada en la práctica totalidad de los proyectos posteriores, incluso por aquellos arquitectos que habían ensayado ya múltiples soluciones de doble núcleo como el propio Barquín, que empleará este modelo en la última de sus incursiones sobre esta tipología, 


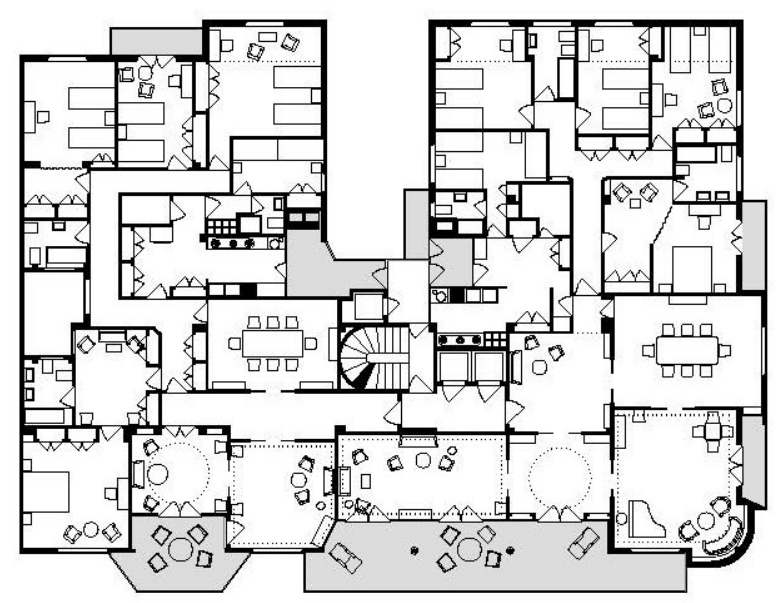

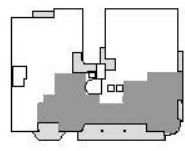

Representacion

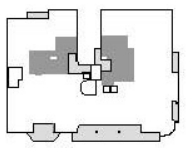

Servicio

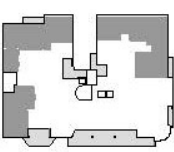

Descanso

Figura 14. Planta Tipo y esquenas de uso. Inmueble nº 10 Avda. República Argentina. Fernando Barquín y Barón. Escala 1:400. Dibujo del autor.
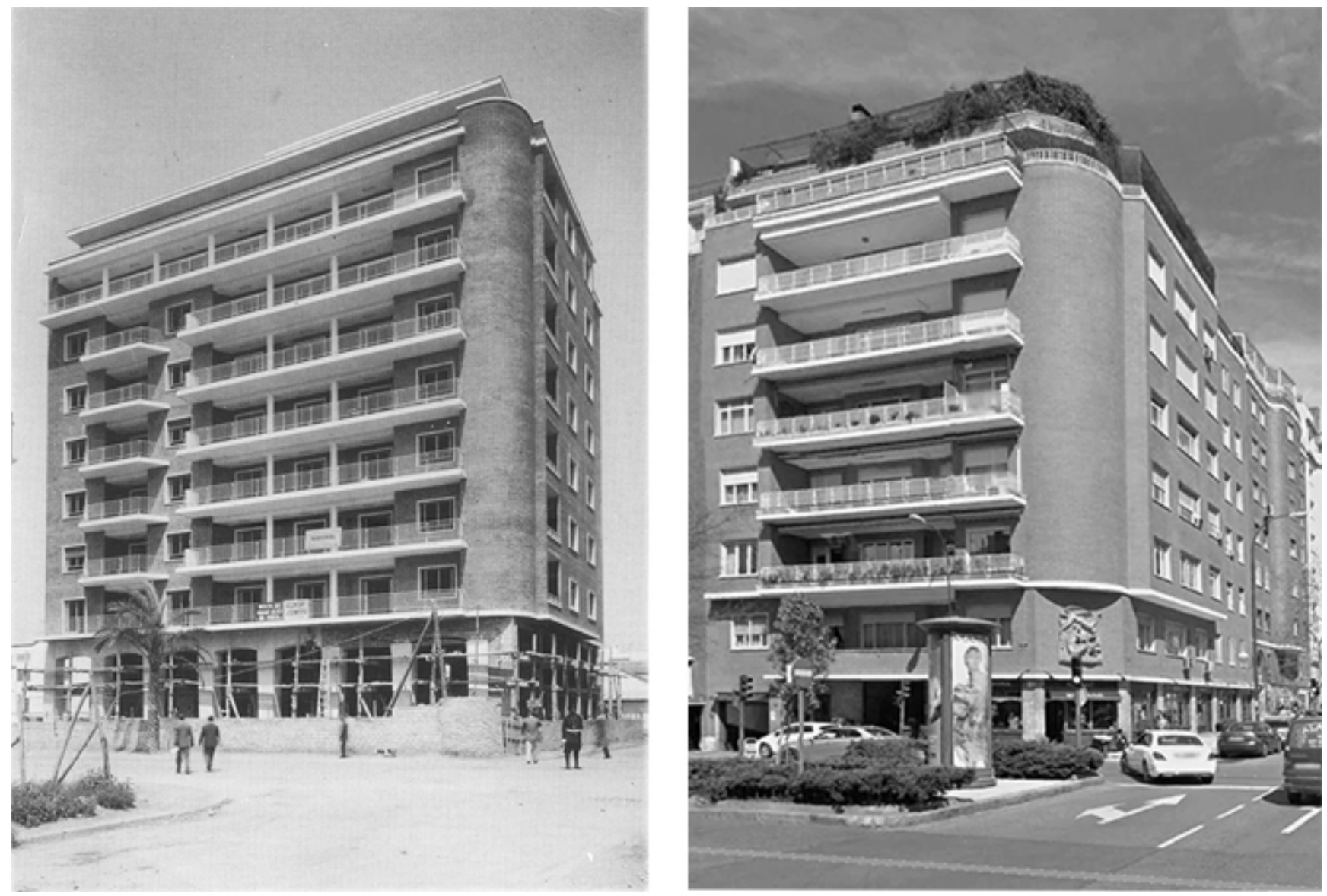

Figura 15. Izquierda. Inmueble n ${ }^{0} 10$ Avda. República Argentina. Fernando Barquín y Barón. 1955. Fuente A.H.M. Sevilla. Derecha. Inmueble c/Juan Bravo Murillo es. Velázquez. Luis Gutiérrez Soto. 1951. Fotografía del autor. 
el inmueble $\mathrm{n}^{0} 10$ de la Avda. República Argentina de 1955 (Figura 14).

En el que la influencia de Gutiérrez Soto alcanzará también a la fachada, muy similar a la del edifico de c/ Juan Bravo Murillo c/v Velázquez (Figura 15).

Es importante destacar que hasta esa fecha, todas las soluciones proyectadas por Barquín, como los números 5 y 6 de la manzana 164 (1953) y los $n^{0} 16,18,20$ de la manzana 156 (1954-55), ambas en el ensanche de Los Remedios y proyectados, estos últimos, junto a Ricardo Espiau, o los inmuebles para la c/ Felipe II (1955) y los bloques 4, 5, y 6 de la Avda. de
Eduardo Dato (1954-55), habían resultado más complejas y siempre de doble núcleo (6).

Finalmente Ricardo Abaurre y Luis Díaz del Río, muy alejados estilísticamente del maestro madrileño, tomarán su obra como modelo paradigmático en el que basar la definición del programa, la organización de los usos y la dotación de equipamiento que habrían de contener sus proyectos, en muchas ocasiones promovidos mediante comunidades de propietarios, que a su vez encontrarían, en los inmuebles proyectados por Luis Gutiérrez Soto para la Plaza de Cuba el referente ineludible de la Vivienda Máxima en la ciudad de Sevilla.

\section{REFERENCIAS}

(1) AA. VV. (1982): La Obra de Luis Gutiérrez Soto. Madrid: COAM, Comisión de Cultura.

(2) AA. VV. (2009): La Vivienda Moderna; DOCOMOMO Ibérico 1925-1965. Barcelona: Fundación Caja de Arquitectos.

(3) Vázquez Consuegra, G.(1992): Guía de Arquitectura de Sevilla. Consejería Obras Públicas y Transportes. Dirección Arquitectura y Vivienda.

(4) Baldellou Santolaria, M.A. (1997): Luis Gutiérrez Soto. Madrid: Electa. Fundación COAM y Ministerio de Fomento. Págs 93-99.

(5) Rincón de la Vega, D. (2010): Una inflexión en la arquitectura de posguerra. Madrid 1955-1970. Vivienda colectiva de lujo (Tesis no publicada). Sevilla: Universidad de Sevilla. ETSA.

(6) Gentil Baldrich, J.M. y Yanguas Álvarez de Toledo, A. (2007): Fernando Barquín y Barón - Joaquín Barquín y Barón. Imágenes de su archivo en los fondos FIDAS. Sevilla: FIDAS/COAS. 